\title{
Thyroid Hormone Replacement Therapy Attenuates the Decline of Renal Function in Chronic Kidney Disease Patients with Subclinical Hypothyroidism
}

\author{
Dong Ho Shin, ${ }^{1}$ Mi Jung Lee, ${ }^{2}$ Hye Sun Lee, ${ }^{3}$ Hyung Jung Oh, ${ }^{2}$ Kwang II Ko, ${ }^{2}$ Chan Ho Kim, ${ }^{2}$ \\ Fa Mee Doh, ${ }^{2}$ Hyang Mo Koo, ${ }^{2}$ Hyoung Rae Kim, ${ }^{2}$ Jae Hyun Han, ${ }^{2}$ Jung Tak Park, ${ }^{2}$ \\ Seung Hyeok Han, ${ }^{2}$ Tae-Hyun Yoo, ${ }^{2}$ and Shin-Wook Kang ${ }^{2,4}$
}

Background: Subclinical hypothyroidism (SCH) is not a rare condition in females, the elderly, or patients with chronic kidney disease (CKD). Even though previous studies have demonstrated that thyroid hormone replacement therapy (THRT) improves cardiac function and dyslipidemia in patients with $\mathrm{SCH}$, it remains unclear as to whether THRT can improve renal function in CKD patients with SCH. This study investigated the impact of THRT on changes in estimated glomerular filtration rates (eGFR) in this patient population.

Methods: A total of 113 CKD patients with SCH who were treated with L-thyroxine and had eGFR available for at least 24 months before and after THRT were enrolled between January 2005 and December 2011. A linear mixed model was used to compare patients' clinical and biochemical parameters at various time points. The slope of the decline in eGFR over time, both before and after THRT, was also calculated and compared using a linear mixed model.

Results: The mean age of the study participants was $63.2 \pm 12.7$ years, and 36 patients $(31.9 \%)$ were men. The mean follow-up duration before and after THRT was 28.6 \pm 4.5 and $30.6 \pm 6.4$ months respectively. After 24 months of THRT, serum thyrotropin (TSH) levels were significantly reduced-8.86 \pm 0.49 versus $1.41 \pm 0.73 \mu \mathrm{IU} /$ $\mathrm{mL}, p<0.001-$ but there were no significant changes in triiodothyronine and free thyroxine concentrations. Serum albumin, calcium, phosphate, cholesterol, and triglyceride levels were also comparable before and after THRT. The rates of decline in eGFR were significantly attenuated by THRT $(-4.31 \pm 0.51 \mathrm{vs} .-1.08 \pm 0.36$ [mL/ $\mathrm{min}$ ]/[year $\cdot 1.73 \mathrm{~m}^{2}$ ], $p<0.001$ ), even after adjustment for age, sex, diabetes, mean arterial pressure, and serum albumin, cholesterol, and triglyceride concentrations $(p<0.001)$.

Conclusion: THRT attenuated the rate of decline in renal function in CKD patients with SCH, suggesting that THRT may delay reaching end-stage renal disease in these patients.

\section{Introduction}

$T$ HYROID HORMONE AFFECTS nearly all organ systems in the body. In the kidney, it is involved in renal development and growth, as well as sodium and water homeostasis (1). Renal plasma flow (RPF) and glomerular filtration rate (GFR) are also known to be influenced by thyroid hormone (1). Accordingly, hyponatremia, reduced RPF and GFR, and elevated serum creatinine concentrations are frequently observed in patients with primary hypothyroidism, and these changes can be normalized by thyroid hormone replacement therapy (THRT) $(1,2)$. In addition, previous case studies have demonstrated that L-thyroxine reversed acute renal failure and a rapid deterioration of underlying chronic renal insufficiency in patients with overt hypothyroidism (3-5).

Subclinical hypothyroidism (SCH), defined as elevated serum thyrotropin (TSH) but normal free thyroxine (fT4) levels, is not a rare disease (6). The prevalence of SCH has been reported to be $\sim 4-10 \%$ in the adult population, and increases with age, especially in women over the age of 45 years (6). Moreover, previous studies have shown a close interrelationship between chronic kidney disease (CKD) and SCH (710). SCH has been frequently observed in $\operatorname{CKD}$ patients $(9,10)$, and a high prevalence of CKD has been found in patients with

\footnotetext{
${ }^{1}$ Department of Internal Medicine, Kangdong Sacred Heart Hospital, College of Medicine, Hallym University, Seoul, South Korea.

${ }^{2}$ Department of Internal Medicine and ${ }^{3}$ Biostatistics Collaboration Unit, College of Medicine; ${ }^{4}$ Severance Biomedical Science Institute Brain Korea 21; Yonsei University, Seoul, South Korea.
} 
overt hypothyroidism as well as $\mathrm{SCH}$ (7). An increased risk of nephropathy but not retinopathy has also been associated with SCH in patients with type 2 diabetes (8).

Replacement of thyroid hormone is fundamental to the treatment of primary hypothyroidism. It relieves the symptoms of hypothyroidism and also alleviates the deleterious effects of overt hypothyroidism on the kidney $(3-5,11)$. Even though previous studies have demonstrated that L-thyroxine improves cardiac function and dyslipidemia in patients with SCH (12-14), there is still a lack of consensus in current guidelines on whether to treat $\mathrm{SCH}$ patients with thyroid hormone or not (15). In particular, little is known about the effect of thyroid hormone replacement on the changes in GFR in CKD patients with SCH. Recently, we demonstrated that thyroid hormone therapy not only preserved renal function better, but was also an independent predictor of renal outcomes in CKD patients with SCH (16). However, in that study, the changes in GFR were just compared between two different study populations: $\mathrm{SCH}$ patients with and without THRT. Therefore, the direct impact of thyroid hormone treatment on the changes in GFR in the same individuals with SCH could not be evaluated. In the present study, we compared the changes in GFR before and after thyroid hormone replacement in the same population of adult CKD patients with $\mathrm{SCH}$.

\section{Methods}

\section{Ethics statement}

This study was carried out in accordance with the Declaration of Helsinki and approved by the Institutional Review Board (IRB) of Yonsei University Health System, Seoul, South Korea. Since the present study was a retrospective medicalrecord-based study and the study subjects were de-identified, the IRB waived the need for written consent from the patients.

\section{Study subjects}

For this study, we initially selected clinically stable stage 2-4 CKD patients who were treated with L-thyroxine for SCH at Yonsei University Health System between January 2005 and December 2011. We excluded patients who were $<18$ or $>75$ years of age, were pregnant, had heavy proteinuria including nephrotic syndrome or terminal malignancy, and were followed up for $<24$ months both before and after THRT. Patients in whom serum creatinine levels were not available at least four times both before and after L-thyroxine treatment were also excluded. Furthermore, we excluded patients who experienced acute exacerbation of underlying renal insufficiency due to dehydration, radiocontrast dye, urinary tract obstruction, or other reasons. In the end, 113 patients were included in the final analysis.

\section{Data collection}

Demographic and clinical data, including age, sex, blood pressure, and co-morbidities such as cardiovascular disease, were recorded at the commencement of THRT. Cardiovascular disease was defined as a history of coronary, cerebrovascular, or peripheral vascular disease; coronary disease was defined as a history of angioplasty, coronary artery bypass grafts, myocardial infarction, or angina; cerebrovascular disease was defined as a previous history of transient ischemic attack, stroke, or carotid endarterectomy; and peripheral vascular disease was defined as a history of claudication, ischemic limb loss and/or ulceration, or peripheral revascularization procedure. The results of laboratory tests, including serum calcium, phosphate, albumin, total cholesterol, and triglyceride concentrations and urinary protein-to-creatinine ratio were also collected. Estimated GFR (eGFR; $[\mathrm{mL} / \mathrm{min}] /$ $1.73 \mathrm{~m}^{2}$ ) was calculated using the four-variable Modification of Diet in Renal Disease study (MDRD) equation (17):

$$
\begin{aligned}
\operatorname{eGFR}\left([\mathrm{mL} / \mathrm{min}] / 1.73 \mathrm{~m}^{2}\right)= & 175 \times(\text { serum creatinine })^{-1.154} \\
& \times \operatorname{age}^{-0.203} \times \operatorname{sex}
\end{aligned}
$$

where sex $=1$ for men or 0.742 for women.

\section{Thyroid function test and definition}

In all the patients, serum triiodothyronine (T3), fT4, TSH, and anti-thyroid peroxidase antibody (TPOAb) levels were measured. Serum T3, fT4, and TSH concentrations were determined by chemiluminescence microparticle immunoassay on the Architect-i2000SR analyzer (Abbott Laboratories, Abbott Park, IL), and TPOAb levels by chemiluminescence assay on the Roche Cobas E601 analyzer (Hitachi, Hitachinaka, Japan). The diagnosis of $\mathrm{SCH}$ was solely based on the results of a thyroid function test and was defined as normal serum $\mathrm{fT} 4$ but elevated TSH concentrations regardless of clinical symptoms of hypothyroidism. Since there was a possibility of transient elevation of serum TSH levels, the measurement of serum TSH concentrations was repeated within three months to confirm the diagnosis. The reference ranges of T3, fT4, and TSH were $0.58-1.59 \mathrm{ng} / \mathrm{mL}$, $0.70-1.48 \mathrm{ng} / \mathrm{dL}$, and $0.35-4.94 \mu \mathrm{IU} / \mathrm{mL}$ respectively.

\section{Treatment of $\mathrm{SCH}$}

All the patients took one brand of L-thyroxine (Synthyroid; Bukwang Pharmacy Co., Ltd., Seoul, South Korea) by pharmacybased dispense. They were initially administered the lowest dose of L-thyroxine necessary to normalize serum TSH levels, which was usually $25 \mu \mathrm{g}$ daily. After the start of thyroid hormone supplement, serum TSH concentrations were remeasured at five or six weeks in most patients. If the levels of TSH remained above the normal reference range, the dose of L-thyroxine was increased by $25 \mu \mathrm{g} /$ day until the patient's serum TSH concentration was reduced to the reference range. The dose of L-thyroxine was adjusted every three months according to the follow-up levels of TSH.

\section{Statistical analysis}

Statistical analysis was performed using SAS (v. 9.1.3; SAS Institute, Inc., Cary, NC). Continuous variables were expressed as mean \pm standard deviation (SD), and categorical variables as a number (percentage). We compared patients' clinical and biochemical parameters at the following time points using a linear mixed model: 24 and 12 months before L-thyroxine, the time of initiation of thyroid hormone supplement, and at 12 and 24 months after L-thyroxine treatment. The post-hoc analysis was performed with Bonferroni correction. The data analyzed by a linear mixed model were expressed as estimate coefficient ( $\beta$ ) and standard error (SE). The slopes of the decline in renal function over time, expressed as $\beta\left([\mathrm{mL} / \mathrm{min}] /\right.$ [year $\left.\left.\cdot 1.73 \mathrm{~m}^{2}\right]\right)$, both before and after THRT, were also calculated and compared using a linear mixed 
model. In addition, further comparison was made after adjusting for age, sex, diabetes, mean arterial pressure, serum albumin, cholesterol, and triglyceride concentrations. Based on the pre- and posttreatment slopes of decline in eGFR, the numbers of patients supposed to reach end-stage renal disease were extrapolated using a linear regression analysis. Pearson's correlation was conducted to elucidate the relationships of eGFR with TSH and T3 levels. A $p$-value of $<0.05$ was considered statistically significant.

\section{Results}

\section{Baseline characteristics of patients}

The demographic, clinical, and biochemical data of the patients at the time of commencement of thyroid hormone (baseline) are listed in Table 1. The mean age was 63.2 \pm 12.7 years, and 36 patients $(31.9 \%)$ were men. The most common cause of CKD was diabetic nephropathy $(38.9 \%)$, followed by hypertension (37.2\%) and chronic glomerulonephritis (15.1\%). Among the 113 patients, 44 (38.9\%) had diabetes and $69(61.1 \%)$ had hypertension. The mean T3, fT4, and TSH concentrations at baseline were $1.08 \pm 0.29 \mathrm{ng} / \mathrm{mL}, 1.09 \pm 0.22 \mathrm{ng} / \mathrm{dL}$, and
$8.86 \pm 5.71 \mu \mathrm{IU} / \mathrm{mL}$ respectively. The patients were divided into two groups based on baseline eGFR: 57 patients had an eGFR $\geq 60(\mathrm{~mL} / \mathrm{min}) / 1.73 \mathrm{~m}^{2}$ (stage $\left.2 \mathrm{CKD}\right)$, and 56 patients had an eGFR $<60(\mathrm{~mL} / \mathrm{min}) / 1.73 \mathrm{~m}^{2}$ (stage $3-4$ CKD). Compared to stage $3-4 \mathrm{CKD}$ patients, the proportions of patients with diabetes $(24.6 \%$ vs. $53.6 \%, p=0.001)$ and hypertension $(50.9 \%$ vs. $71.4 \%, p=0.03)$ were significantly lower in the stage 2 CKD group. In addition, T3 levels were significantly higher $(1.19 \pm 0.28$ vs. $0.98 \pm 0.27 \mathrm{ng} / \mathrm{mL}, p<0.001)$, while TSH concentrations were significantly lower $(7.74 \pm 3.95$ vs. $10.00 \pm 6.93 \mu \mathrm{IU} / \mathrm{mL}, p=0.04)$ in patients with stage $2 \mathrm{CKD}$ (Table 1). Meanwhile, Pearson's correlation analysis revealed that there was a significant inverse correlation between baseline eGFR and TSH levels $(r=-0.31, p=0.001)$ and significant positive associations of baseline eGFR with serum T3 $(r=0.38$, $p<0.001)$ and fT4 concentrations $(r=0.22, p=0.02$; Fig. 1$)$.

\section{Changes in clinical and biochemical parameters after THRT}

As shown in Table 2, the mean TSH levels at 12 and 24 months of L-thyroxine treatment, $1.62 \pm 0.92$ and $1.41 \pm 0.73 \mu \mathrm{IU} / \mathrm{mL}$ respectively, were significantly lower than the baseline of

Table 1. Demographic, Clinical, and Biochemical Characteristics of the Patients at the Time of Commencement of Thyroid Hormone Replacement Therapy

\begin{tabular}{|c|c|c|c|c|}
\hline & Total $(\mathrm{n}=113)$ & $e G F R \geq 60(\mathrm{n}=57)$ & $e G F R<60(\mathrm{n}=56)$ & $\mathrm{p}$-Value \\
\hline Age (years) & $63.2 \pm 12.7$ & $59.0 \pm 12.4$ & $67.5 \pm 11.5$ & $<0.001$ \\
\hline Men & 36 (31.9\%) & $16(28.1 \%)$ & $20(35.7 \%)$ & 0.38 \\
\hline $\mathrm{DM}$ & $44(38.9 \%)$ & $14(24.6 \%)$ & $30(53.6 \%)$ & 0.001 \\
\hline Hypertension & $69(61.1 \%)$ & $29(50.9 \%)$ & $40(71.4 \%)$ & 0.02 \\
\hline Cardiovascular disease & $17(15.0 \%)$ & $8(14 \%)$ & $9(16.1 \%)$ & 0.76 \\
\hline \multicolumn{5}{|l|}{ Primary disease } \\
\hline Diabetic nephropathy & $44(38.9 \%)$ & $14(24.6 \%)$ & $30(53.6 \%)$ & 0.001 \\
\hline Hypertensive nephrosclerosis & $42(37.2 \%)$ & $22(38.6 \%)$ & $20(35.7 \%)$ & 0.02 \\
\hline Chronic GN & $17(15.1 \%)$ & $13(22.8 \%)$ & $4(7.1 \%)$ & 0.32 \\
\hline Tubulointersitial nephritis & $6(5.3 \%)$ & $6(10.7 \%)$ & $0(0 \%)$ & 0.01 \\
\hline Others & $4(3.5 \%)$ & $3(5.3 \%)$ & $1(1.8 \%)$ & 0.32 \\
\hline Systolic blood pressure (mmHg) & $148.9 \pm 17.8$ & $144.4 \pm 12.6$ & $152.0 \pm 20.3$ & 0.90 \\
\hline Diastolic blood pressure (mmHg) & $86.5 \pm 11.0$ & $85.6 \pm 8.3$ & $87.2 \pm 12.6$ & 0.59 \\
\hline Mean arterial pressure $(\mathrm{mmHg})$ & $107.3 \pm 11.7$ & $105.2 \pm 8.8$ & $108.8 \pm 13.4$ & 0.26 \\
\hline \multicolumn{5}{|l|}{ Thyroid function test } \\
\hline $\mathrm{T} 3(\mathrm{ng} / \mathrm{mL})$ & $1.08 \pm 0.29$ & $1.19 \pm 0.28$ & $0.98 \pm 0.27$ & $<0.001$ \\
\hline $\mathrm{fT} 4(\mathrm{ng} / \mathrm{dL})$ & $1.09 \pm 0.22$ & $1.11 \pm 0.22$ & $1.08 \pm 0.22$ & 0.47 \\
\hline $\mathrm{TSH}(\mu \mathrm{IU} / \mathrm{mL})$ & $8.86 \pm 5.71$ & $7.74 \pm 3.95$ & $10.00 \pm 6.93$ & 0.04 \\
\hline Anti-TPO $\geq 60 \mathrm{IU} / \mathrm{mL}$ ) & $45(39.8 \%)$ & $24(44.4 \%)$ & $21(38.9 \%)$ & 0.56 \\
\hline Serum creatinine (mg/dL) & $1.28 \pm 0.50$ & $1.01 \pm 0.20$ & $1.56 \pm 0.56$ & $<0.001$ \\
\hline $\mathrm{eGFR}\left([\mathrm{mL} / \mathrm{min}] / 1.73 \mathrm{~m}^{2}\right)$ & $59.5 \pm 16.3$ & $72.5 \pm 7.7$ & $46.2 \pm 11.2$ & $<0.001$ \\
\hline Serum albumin (g/dL) & $4.03 \pm 0.89$ & $4.01 \pm 0.93$ & $4.05 \pm 0.86$ & 0.80 \\
\hline Serum calcium $(\mathrm{mg} / \mathrm{dL})$ & $9.26 \pm 0.65$ & $9.27 \pm 0.67$ & $9.24 \pm 0.65$ & 0.76 \\
\hline Serum phosphate (mg/dL) & $3.84 \pm 0.59$ & $3.91 \pm 0.57$ & $3.76 \pm 0.60$ & 0.18 \\
\hline Serum cholesterol (mg/dL) & $171.2 \pm 35.5$ & $171.4 \pm 34.5$ & $171.0 \pm 36.7$ & 0.07 \\
\hline Serum triglyceride (mg/dL) & $156.4 \pm 111.8$ & $138.8 \pm 92.7$ & $176.1 \pm 128.4$ & 0.13 \\
\hline \multicolumn{5}{|l|}{ Medication use } \\
\hline RAS blockers & $78(69.0 \%)$ & $42(73.7 \%)$ & $36(64.3 \%)$ & 0.28 \\
\hline Calcium channel blockers & $37(32.7 \%)$ & $15(26.3 \%)$ & $22(39.3 \%)$ & 0.14 \\
\hline$\beta$-blockers & $30(26.5 \%)$ & $13(43.3 \%)$ & $17(56.7 \%)$ & 0.36 \\
\hline Diuretics & $43(38.1 \%)$ & $18(31.6 \%)$ & $25(44.6 \%)$ & 0.15 \\
\hline Other antihypertensive drugs & $5(4.4 \%)$ & $3(5.4 \%)$ & $2(3.8 \%)$ & 0.71 \\
\hline Statins & $36(31.9 \%)$ & $18(31.6 \%)$ & $18(32.1 \%)$ & 0.95 \\
\hline
\end{tabular}

Values are expressed as mean \pm standard deviation or number (percentage).

DM, diabetes mellitus; eGFR, estimated glomerular filtration rate (by MDRD-4 equation); fT4, free thyroxine; GN, glomerulonephritis; RAS, renin-angiotensin system; TPOAb, anti-thyroid peroxidase antibody; TSH, thyrotropin; T3, triiodothyronine. 

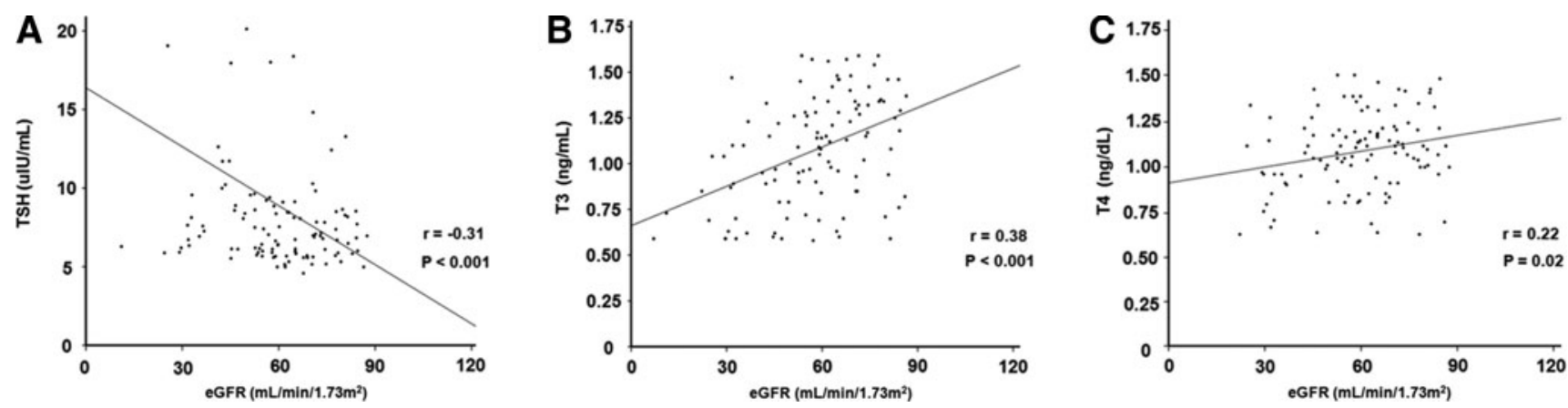

FIG. 1. Relationship of baseline estimated glomerular filtration rate (eGFR) with baseline serum thyrotropin (TSH) (A), triiodothyronine (T3) (B), and free thyroxine (fT4) levels (C). Data are presented as correlation coefficients $(r)$ and $p$-values.

$8.86 \pm 0.44 \mu \mathrm{IU} / \mathrm{mL}(p<0.001)$. In contrast, there were no significant changes in blood pressure, serum T3, fT4, albumin, total cholesterol, and triglyceride concentrations, and the amount of proteinuria after THRT (Table 2). These clinical and biochemical changes were similar even when the analysis was performed separately in patients with stage 2 and stage $3-4$ CKD (Tables 3 and 4).

\section{Comparison of the rates of eGFR decline before and after THRT}

The overall rate of decline in eGFR was significantly blunted from $-4.14 \pm 0.36$ to $-1.16 \pm 0.25$ (mL/min)/ (year $\left.\cdot 1.73 \mathrm{~m}^{2}\right)(p<0.001)$ by THRT (Fig. 2A). The impact of thyroid hormone on the decline in eGFR remained statistically significant even after adjusting for age, sex, diabetes, mean arterial pressure, serum albumin, cholesterol, and triglyceride levels $\left(-4.31 \pm 0.51\right.$ vs. $-1.08 \pm 0.36[\mathrm{~mL} / \mathrm{min}] /$ [year $\left.\cdot 1.73 \mathrm{~m}^{2}\right]$, $p<0.001)$. The numbers of patients who had a slower, faster, or unchanged eGFR decline after THRT compared to their pretreatment rates of decline in eGFR were determined. Based on the changes of more than $\pm 5 \%$ compared to the pretreat- ment values, $72(63.7 \%)$ patients experienced a slower decline in eGFR, while $7(6.2 \%)$ and $34(30.1 \%)$ patients had a faster and unchanged eGFR decline after treatment.

To investigate whether the effect of THRT on the decline in eGFR varied among patients with different baseline eGFR, a subgroup analysis was also conducted. As seen in Figure 2B and $\mathrm{C}$, the rates of decline in eGFR were significantly attenuated by L-thyroxine supplement in both stage $2(p<0.001)$ and stage $3-4$ CKD patients $(p<0.001)$.

We further determined and compared the rates of decline in eGFR according to the status of TPOAb, as well as serum TSH concentrations. The patients were first divided into two groups based on TPOAb status; Hashimoto's and nonHashimoto's SCH, and the changes in eGFR before and after treatment were compared in the two groups. In the Hashimoto's group, the overall rate of decline in eGFR before THRT was $-3.84 \pm 0.54(\mathrm{~mL} / \mathrm{min}) /\left(\right.$ year $\left.\cdot 1.73 \mathrm{~m}^{2}\right)$, which was significantly blunted to $-0.63 \pm 0.38(\mathrm{~mL} / \mathrm{min}) /($ year $\cdot 1.73$ $\left.\mathrm{m}^{2}\right)$ after L-thyroxine supplement $(p<0.001)$. There was also a significant difference in the rates of decline in eGFR before and after THRT in the non-Hashimoto's group, $-4.34 \pm 0.47$ versus $-1.52 \pm 0.33(\mathrm{~mL} / \mathrm{min}) /\left(\right.$ year $\left.\cdot 1.73 \mathrm{~m}^{2}\right) \quad(p<0.001$;

Table 2. Changes in Clinical and Biochemical Parameters Over Time in All Patients

\begin{tabular}{|c|c|c|c|c|c|c|}
\hline & \multicolumn{5}{|c|}{ Time (months) } & \multirow[b]{2}{*}{$\mathrm{p}$-Value } \\
\hline & -24 & -12 & Baseline $^{\mathrm{a}}$ & +12 & +24 & \\
\hline SBP (mmHg) & $147.1 \pm 2.5$ & $148.5 \pm 2.5$ & $148.9 \pm 2.6$ & $147.5 \pm 2.6$ & $149.2 \pm 2.1$ & 0.97 \\
\hline $\mathrm{DBP}(\mathrm{mmHg})$ & $85.1 \pm 1.5$ & $85.4 \pm 1.5$ & $86.5 \pm 1.5$ & $84.1 \pm 1.5$ & $82.7 \pm 1.3$ & 0.39 \\
\hline \multicolumn{7}{|l|}{ Thyroid function test } \\
\hline $\mathrm{T} 3 \pm \mathrm{ng} / \mathrm{mL}$ & $1.15 \pm 0.03$ & $1.09 \pm 0.03$ & $1.08 \pm 0.03$ & $1.11 \pm 0.03$ & $1.08 \pm 0.03$ & 0.44 \\
\hline $\mathrm{fT} 4 \pm \mathrm{ng} / \mathrm{dL}$ & $1.13 \pm 0.03$ & $1.09 \pm 0.03$ & $1.10 \pm 0.02$ & $1.10 \pm 0.03$ & $1.12 \pm 0.03$ & 0.72 \\
\hline $\mathrm{TSH} \pm \mu \mathrm{IU} / \mathrm{mL}$ & $8.52 \pm 0.45$ & $8.02 \pm 0.44$ & $8.86 \pm 0.44$ & $1.62 \pm 0.92^{*}$ & $1.41 \pm 0.73^{*}$ & $<0.001$ \\
\hline eGFR $\left([\mathrm{mL} / \mathrm{min}] / 1.73 \mathrm{~m}^{2}\right)$ & $68.1 \pm 1.6^{*}$ & $64.7 \pm 1.6^{* *}$ & $59.5 \pm 1.6$ & $56.8 \pm 1.8$ & $57.1 \pm 1.6$ & $<0.001$ \\
\hline Serum albumin $(\mathrm{g} / \mathrm{dL})$ & $4.17 \pm 0.06$ & $4.10 \pm 0.06$ & $4.03 \pm 0.06$ & $4.09 \pm 0.06$ & $4.07 \pm 0.06$ & 0.56 \\
\hline Serum calcium (mg/dL) & $9.17 \pm 0.08$ & $9.26 \pm 0.08$ & $9.26 \pm 0.08$ & $9.27 \pm 0.08$ & $9.28 \pm 0.08$ & 0.89 \\
\hline Serum phosphate (mg/dL) & $3.83 \pm 0.06$ & $3.82 \pm 0.06$ & $3.84 \pm 0.06$ & $3.85 \pm 0.06$ & $3.85 \pm 0.06$ & 0.99 \\
\hline Serum cholesterol (mg/dL) & $164.3 \pm 3.8$ & $166.0 \pm 3.9$ & $171.2 \pm 3.9$ & $161.0 \pm 3.9$ & $172.4 \pm 3.8$ & 0.19 \\
\hline Serum triglyceride (mg/dL) & $154.7 \pm 9.3$ & $149.0 \pm 9.9$ & $156.4 \pm 10.3$ & $152.6 \pm 9.9$ & $142.4 \pm 9.2$ & 0.85 \\
\hline Proteinuria (urine $\mathrm{P} / \mathrm{Cr}$ ) & $1.32 \pm 0.09$ & $1.31 \pm 0.09$ & $1.33 \pm 0.09$ & $1.33 \pm 0.09$ & $1.36 \pm 0.09$ & 0.99 \\
\hline L-thyroxine ( $\mu \mathrm{g} /$ day) & & & $25 \pm 0.0$ & $45.4 \pm 2.1^{*}$ & $46.0 \pm 2.1^{*}$ & $<0.001$ \\
\hline
\end{tabular}

Values are expressed as mean \pm standard error.

${ }^{a}$ At the time of commencement of thyroid hormone therapy.

${ }^{*} p<0.001,{ }^{* *} p<0.05$ vs. baseline.

$\mathrm{DBP}$, diastolic blood pressure; $\mathrm{P} / \mathrm{Cr}$, protein-to-creatinine ratio; $\mathrm{SBP}$, systolic blood pressure. 
Table 3. Changes in Clinical and Biochemical Parameters Over Time in Patients with Stage 2 Chronic Kidney Disease

\begin{tabular}{|c|c|c|c|c|c|c|}
\hline & \multicolumn{5}{|c|}{ Time (months) } & \multirow[b]{2}{*}{$\mathrm{p}$-Value } \\
\hline & -24 & -12 & Baseline $^{\mathrm{a}}$ & +12 & +24 & \\
\hline SBP (mmHg) & $142.4 \pm 3.2$ & $143.4 \pm 3.4$ & $144.4 \pm 3.6$ & $140.5 \pm 3.5$ & $148.0 \pm 2.6$ & 0.45 \\
\hline $\mathrm{DBP}(\mathrm{mmHg})$ & $83.8 \pm 2.1$ & $83.7 \pm 2.0$ & $85.6 \pm 2.2$ & $82.5 \pm 2.1$ & $81.2 \pm 1.7$ & 0.60 \\
\hline \multicolumn{7}{|l|}{ Thyroid function test } \\
\hline T3 (ng/mL) & $1.23 \pm 0.04$ & $1.13 \pm 0.04$ & $1.19 \pm 0.04$ & $1.17 \pm 0.04$ & $1.13 \pm 0.04$ & 0.38 \\
\hline fT4 (ng/dL) & $1.14 \pm 0.04$ & $1.13 \pm 0.04$ & $1.11 \pm 0.03$ & $1.09 \pm 0.03$ & $1.13 \pm 0.04$ & 0.83 \\
\hline TSH $(\mu \mathrm{IU} / \mathrm{mL})$ & $8.02 \pm 0.42$ & $7.22 \pm 0.42$ & $7.74 \pm 0.42$ & $1.49 \pm 1.00^{*}$ & $1.57 \pm 0.71^{*}$ & $<0.001$ \\
\hline eGFR $\left([\mathrm{mL} / \mathrm{min}] / 1.73 \mathrm{~m}^{2}\right)$ & $79.8 \pm 1.0^{*}$ & $76.1 \pm 1.0^{* *}$ & $72.5 \pm 1.0$ & $70.6 \pm 1.3$ & $70.2 \pm 1.0$ & $<0.001$ \\
\hline Serum albumin $(g / d L)$ & $4.17 \pm 0.08$ & $4.17 \pm 0.08$ & $4.01 \pm 0.08$ & $4.15 \pm 0.08$ & $4.14 \pm 0.08$ & 0.60 \\
\hline Serum calcium $(\mathrm{mg} / \mathrm{dL})$ & $9.13 \pm 0.11$ & $9.21 \pm 0.11$ & $9.28 \pm 0.11$ & $9.24 \pm 0.12$ & $9.35 \pm 0.12$ & 0.74 \\
\hline Serum phosphate (mg/dL) & $3.83 \pm 0.08$ & $3.78 \pm 0.08$ & $3.90 \pm 0.08$ & $3.88 \pm 0.08$ & $3.85 \pm 0.08$ & 0.79 \\
\hline Serum cholesterol (mg/dL) & $170.3 \pm 5.3$ & $167.4 \pm 5.4$ & $171.4 \pm 5.31$ & $162.5 \pm 5.4$ & $178.4 \pm 5.3$ & 0.32 \\
\hline Serum triglyceride (mg/dL) & $157.6 \pm 12.2$ & $149.0 \pm 13.5$ & $138.8 \pm 13.2$ & $152.2 \pm 13.4$ & $155.3 \pm 12.0$ & 0.86 \\
\hline Proteinuria (urine $\mathrm{P} / \mathrm{Cr}$ ) & $0.97 \pm 0.11$ & $1.03 \pm 0.11$ & $1.11 \pm 0.11$ & $1.12 \pm 0.11$ & $1.16 \pm 0.11$ & 0.72 \\
\hline L-thyroxine ( $\mu \mathrm{g} /$ day) & & & $25.0 \pm 0.0$ & $45.2 \pm 3.0^{* *}$ & $44.7 \pm 3.0^{* *}$ & 0.007 \\
\hline
\end{tabular}

Values are expressed as mean \pm standard error.

${ }^{a}$ At the time of commencement of thyroid hormone therapy.

${ }^{*} p<0.001,{ }^{* *} p<0.05$ vs. baseline.

Supplementary Table S1 and Fig. 3A, B; Supplementary Data are available online at www.liebertpub.com/thy). Next, we divided the patients into two groups based on the baseline TSH levels-high $(>8 \mu \mathrm{IU} / \mathrm{mL})$ and low TSH $(\leq 8 \mu \mathrm{IU} / \mathrm{mL})-$ and we compared the changes in eGFR before and after treatment in the two groups. In the high TSH group, the overall rate of decline in eGFR before THRT was $-3.63 \pm 0.50$ $(\mathrm{mL} / \mathrm{min}) /\left(\right.$ year $\left.\cdot 1.73 \mathrm{~m}^{2}\right)$, which was significantly blunted to $-1.30 \pm 0.35(\mathrm{~mL} / \mathrm{min}) /\left(\right.$ year $\left.\cdot 1.73 \mathrm{~m}^{2}\right)$ after L-thyroxine supplement $(p<0.001)$. There was also a significant difference in the rates of decline in eGFR before and after THRT in the low TSH group, $-4.45 \pm 0.49$ versus $-1.08 \pm 0.34(\mathrm{~mL} / \mathrm{min})$ / $\left(\right.$ year $\left.\cdot 1.73 \mathrm{~m}^{2}\right)(p<0.001$; Supplementary Table S2 and Fig. 4A, $\mathrm{B})$. These findings suggest that the response to THRT did not vary significantly in CKD patients with $\mathrm{SCH}$ according to their TPOAb status and serum TSH concentrations.

\section{Impact of THRT on reaching end-stage renal disease}

Finally, a linear regression analysis was conducted to extrapolate how many patients would reach CKD stage 5, the stage requiring dialysis or kidney transplantation, within 10 years on the basis of the pre- and posttreatment slopes of decline in eGFR. Based on the slope of decline in eGFR before L-thyroxine supplement, 53 (46.9\%) patients were supposed to reach CKD stage 5 within 10 years. However, the estimated number of patients decreased to $10(8.8 \%)$ when the posttreatment slope of decline in eGFR was used, indicating that

Table 4. Changes in Clinical and Biochemical Parameters Over Time in Patients with Stage 3-4 Chronic Kidney Disease

\begin{tabular}{|c|c|c|c|c|c|c|}
\hline & \multicolumn{5}{|c|}{ Time (months) } & \multirow[b]{2}{*}{$\mathrm{p}$-Value } \\
\hline & -24 & -12 & Baseline $^{\mathrm{a}}$ & +12 & +24 & \\
\hline SBP (mmHg) & $151.1 \pm 3.5$ & $152.5 \pm 3.5$ & $152.0 \pm 3.6$ & $152.7 \pm 3.6$ & $150.4 \pm 3.2$ & 0.99 \\
\hline DBP (mmHg) & $86.1 \pm 2.1$ & $86.7 \pm 2.1$ & $87.2 \pm 2.1$ & $85.3 \pm 2.1$ & $84.0 \pm 1.8$ & 0.80 \\
\hline \multicolumn{7}{|l|}{ Thyroid function test } \\
\hline $\mathrm{T} 3(\mathrm{ng} / \mathrm{mL})$ & $1.07 \pm 0.04$ & $1.05 \pm 0.04$ & $0.98 \pm 0.04$ & $1.03 \pm 0.04$ & $1.04 \pm 0.04$ & 0.65 \\
\hline fT4 (ng/dL) & $1.12 \pm 0.04$ & $1.04 \pm 0.04$ & $1.08 \pm 0.03$ & $1.10 \pm 0.03$ & $1.11 \pm 0.04$ & 0.60 \\
\hline TSH $(\mu \mathrm{IU} / \mathrm{mL})$ & $9.03 \pm 0.78$ & $8.83 \pm 0.78$ & $9.99 \pm 0.77$ & $1.69 \pm 1.44^{*}$ & $1.27 \pm 1.23^{*}$ & $<0.001$ \\
\hline eGFR $\left([\mathrm{mL} / \mathrm{min}] / 1.73 \mathrm{~m}^{2}\right)$ & $56.1 \pm 1.7^{*}$ & $52.8 \pm 1.7^{* *}$ & $46.2 \pm 1.7$ & $45.6 \pm 1.9$ & $43.8 \pm 1.7$ & $<0.001$ \\
\hline Serum albumin $(g / d L)$ & $4.16 \pm 0.08$ & $4.04 \pm 0.08$ & $4.05 \pm 0.08$ & $4.02 \pm 0.09$ & $4.00 \pm 0.09$ & 0.67 \\
\hline Serum calcium (mg/dL) & $9.22 \pm 0.11$ & $9.30 \pm 0.11$ & $9.24 \pm 0.11$ & $9.29 \pm 0.11$ & $9.21 \pm 0.11$ & 0.97 \\
\hline Serum phosphate (mg/dL) & $3.82 \pm 0.09$ & $3.85 \pm 0.09$ & $3.76 \pm 0.09$ & $3.82 \pm 0.09$ & $3.85 \pm 0.09$ & 0.96 \\
\hline Serum cholesterol (mg/dL) & $158.2 \pm 5.5$ & $164.5 \pm 5.6$ & $171.0 \pm 5.6$ & $159.4 \pm 5.6$ & $166.4 \pm 5.5$ & 0.47 \\
\hline Serum triglyceride (mg/dL) & $151.6 \pm 14.0$ & $149.0 \pm 14.3$ & $176.2 \pm 15.9$ & $152.9 \pm 14.6$ & $128.7 \pm 14.0$ & 0.28 \\
\hline Proteinuria (urine $\mathrm{P} / \mathrm{Cr}$ ) & $1.68 \pm 0.13$ & $1.58 \pm 0.13$ & $1.55 \pm 0.13$ & $1.53 \pm 0.13$ & $1.56 \pm 0.13$ & 0.93 \\
\hline L-thyroxine ( $\mu \mathrm{g} /$ day) & & & $25.0 \pm 0.0$ & $45.5 \pm 2.9^{* *}$ & $47.3 \pm 2.9^{* *}$ & 0.002 \\
\hline
\end{tabular}

Values are expressed as mean \pm standard error.

${ }^{a}$ At the time of commencement of thyroid hormone therapy.

${ }^{*} p<0.001,{ }^{* *} p<0.01$ vs. baseline. 

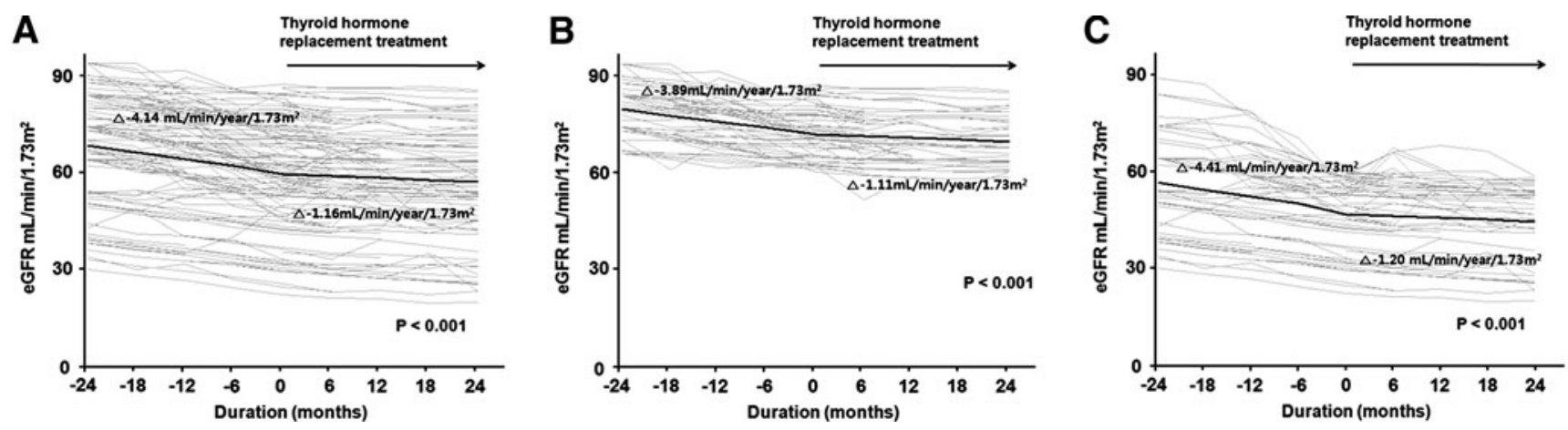

FIG. 2. Changes in eGFR over time in all patients (A), patients with stage 2 chronic kidney disease (B), and patients with stage 3-4 chronic kidney disease (C). Gray lines represent individual patient measurements, and solid lines represent predicted slopes.

THRT delayed reaching CKD stage 5 within 10 years in $81.1 \%$ $(43 / 53)$ of CKD patients with SCH.

\section{Discussion}

Even though previous studies have demonstrated that restoration of euthyroidism has beneficial effects on cardiac dysfunction in patients with SCH $(13,14)$, the impact of THRT on renal function has not been extensively explored in these patients. The results of the present study show for the first time that thyroid hormone treatment significantly abrogated the decrease in eGFR in CKD patients with SCH.

$\mathrm{SCH}$, diagnosed purely biochemically by elevated serum TSH but normal fT4 concentrations, is not a rare disorder in CKD patients $(6,9,10)$. The data of 14,623 adult participants from the third National Health and Nutrition Examination Survey (NHANES III), a nationally representative sample of the U.S. population, revealed that the prevalence of hypothyroidism increased with lower levels of GFR, occurring in $10.9 \%$ of patients with stage 2 CKD, $21.0 \%$ with stage 3 CKD, and $23.1 \%$ with stage 4 or 5 CKD (10). Additionally, there was an independently higher risk of hypothyroidism in stage 2-5 CKD patients, even after adjusting for age, sex, and ethnicity (10). Among these hypothyroidism patients, 56\% were considered subclinical (10). Moreover, Chonchol et al. (9) showed that the prevalence of SCH increased from $7 \%$ at an eGFR $\geq 90$ ( $\mathrm{mL} / \mathrm{min}) / 1.73 \mathrm{~m}^{2}$ to $17.9 \%$ at an $\mathrm{eGFR}<60(\mathrm{~mL} / \mathrm{min}) /$ $1.73 \mathrm{~m}^{2}$ in 3089 unselected outpatient adults. They also found that patients with stage 3-5 CKD had increased odds of $\mathrm{SCH}$, even after adjusting for age, sex, and fasting plasma glucose, total cholesterol, and triglyceride concentrations. Conversely, a cross-sectional, population-based study of 29,480 individuals over the age of 40 years without previously known thyroid disease demonstrated that the prevalence of CKD was significantly higher in people with TSH in the middle or highest third of the reference range and in people with $\mathrm{SCH}$ than in people with TSH in the lower third of the reference range (7). Furthermore, TSH levels within the normal range were also negatively associated with eGFR (7). In the current study, we did not determine the prevalence of $\mathrm{SCH}$ in CKD patients or the prevalence of CKD in patients with $\mathrm{SCH}$. However, even though the TSH levels of this study subjects were above the normal range, there was a significant negative correlation between eGFR and TSH concentrations, which was in accordance with previous studies $(7,18)$. Meanwhile, T3 levels have commonly been found to decrease in patients with CKD. Moreover, in a recent study of 2284 adults with normal TSH levels, Song et al. (19) demonstrated that there was a tendency for $\mathrm{T} 3$ concentrations to decrease according to the reduction in eGFR. Consistent with the results of the present study, they also showed that eGFR was positively correlated with T3 concentrations.

Since thyroid hormone has numerous effects on the kidney, heart, and the vascular system, thyroid dysfunction can cause significant changes in renal and cardiovascular functions $(1,2,11,20)$. Primary hypothyroidism is known to be associated with a reduced RPF, increased serum creatinine levels, low GFR, decreased renal sodium reabsorption, and decreased renal ability to dilute urine $(1,2)$, and these abnormalities have been found to be ameliorated by L-thyroxine
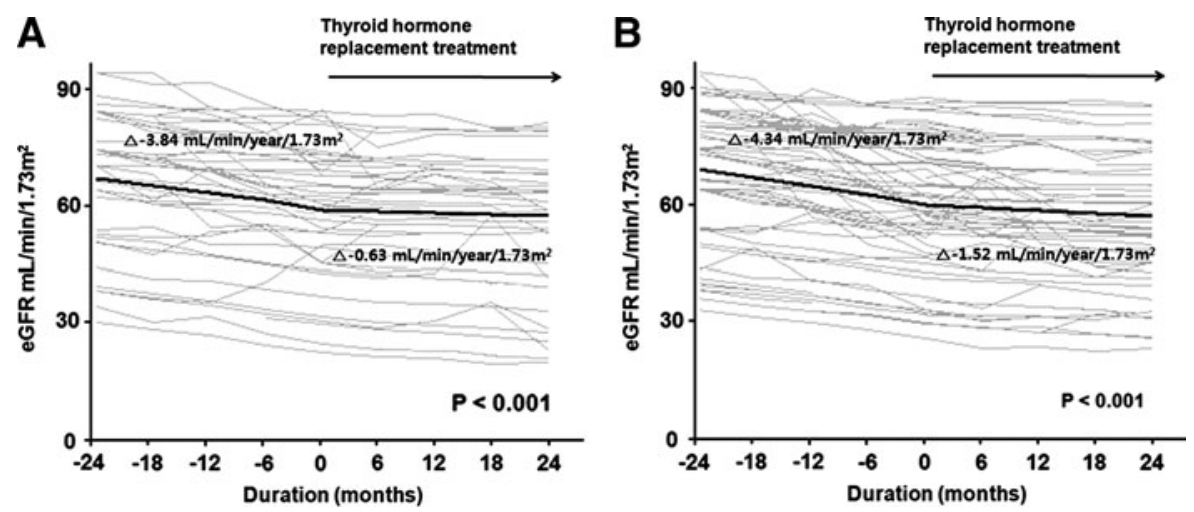

FIG. 3. Changes in eGFR over time in patients with Hashimoto's (A) and non-Hashimoto's subclinical hypothyroidism (B). Gray lines represent individual patient measurements, and solid lines represent predicted slopes. 
FIG. 4. Changes in eGFR over time in patients with baseline serum TSH concentrations $>8 \mu \mathrm{IU} /$ $\mathrm{mL}$ (A) and $\leq 8 \mu \mathrm{IU} / \mathrm{mL}$ (B). Gray lines represent individual patient measurements, and solid lines represent predicted slopes.

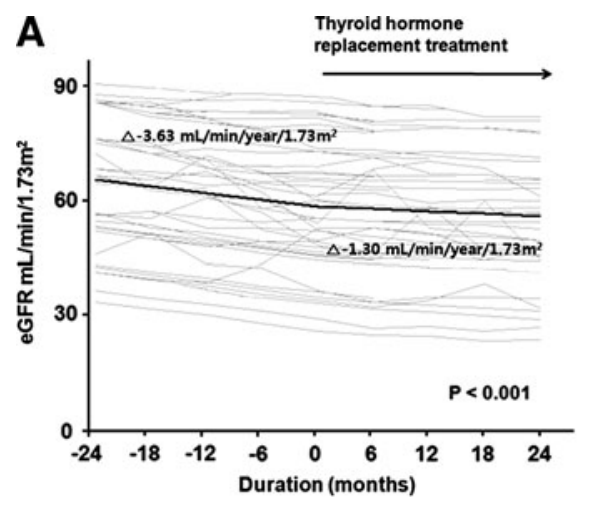

supplementation $(3-5,11)$. Likewise, THRT reverses the cardiovascular derangements associated with overt hypothyroidism, including bradycardia, diastolic hypertension along with narrowed pulse pressure, decreased cardiac contractility, decreased cardiac output, and increased systemic vascular resistance (20). However, these renal and cardiovascular abnormalities are not common in patients with $\mathrm{SCH}$. A previous study demonstrated that plasma volume, RPF, and GFR were significantly reduced in patients with overt hypothyroidism, whereas blood volume remained normal in patients with $\mathrm{SCH}$, partly explaining the reason why renal derangement was rarely observed in patients with SCH (21). In contrast, some cases of cardiac dysfunction accompanied by SCH were shown to be attenuated by thyroid hormone treatment $(13,14)$. Moreover, flow-mediated dilatation (FMD), a marker of endothelial function, was significantly lower in patients with $\mathrm{SCH}$ compared to euthyroid patients with no differences in biochemical and metabolic parameters $(22,23)$, suggesting that $\mathrm{SCH}$ may have adverse effects on endothelial function independent from other well-known atherosclerotic risk factors. Furthermore, restoration of euthyroidism by L-thyroxine significantly abrogated the increase in serum total and LDLcholesterol concentrations in SCH patients (12). Based on these findings, as well as the result of the current study demonstrating that there was no significant change in serum total cholesterol levels during THRT, we surmised that the preservation of renal function in CKD patients with SCH may be attributed to improvements in cardiovascular function by thyroid hormone. Further studies that include echocardiography and FMD are necessary to verify our hypothesis.

As previously mentioned, a number of previous studies have found that THRT ameliorates cardiac dysfunction associated with SCH $(13,14)$. In contrast, the effect of thyroid hormone on renal function has not been widely investigated in $\mathrm{SCH}$ patients. We recently demonstrated that thyroid hormone treatment not only preserved renal function, but was also an independent predictor of renal outcome in CKD patients with SCH (16). In that study, the changes in eGFR were just compared between two different study populations: SCH patients with and without THRT. Thus, in order to clarify the direct impact of thyroid hormone treatment on the decline in renal function, it was imperative to compare the slopes of the decline in eGFR before and after L-thyroxine supplement in the same patients. Moreover, in our previous study, patients with TSH concentrations $>10 \mu \mathrm{IU} / \mathrm{mL}$ were excluded, and the proportion of patients with high TPOAb titers differed between the treatment and nontreatment groups. The results of the present study showed that the slope of the decline in eGFR after THRT was significantly smaller than the slope before treatment, and that the response to L-thyroxine supplement did not vary significantly in our patients according to their $\mathrm{TPOAb}$ status and serum TSH concentrations, suggesting that thyroid hormone significantly attenuated the decline in renal function in $\mathrm{CKD}$ patients with $\mathrm{SCH}$ irrespective of baseline TPOAb titers and TSH levels. In addition, the current study revealed that THRT effectively blunted the decline in renal function in CKD patients with SCH irrespective of baseline eGFR.

Several shortcomings of this study must be addressed. First, the study design was retrospective and not all CKD patients with $\mathrm{SCH}$ were included. To minimize the interference of the time factor in the slope of eGFR changes, we only included patients who were followed at least two years both before and after THRT. Second, the eGFR data were not uniformly available in all patients at regular intervals of 3-6 months. To overcome this problem in the measurement of longitudinal data, we utilized a linear mixed model instead of repeated-measures analysis of variance. In addition, patients with too much missing data were excluded from the final analysis. However, while the excluded patients' data were not intentionally omitted in the analysis, we cannot completely guarantee that there was no selection bias. Third, this study included only a small number of patients with an advanced stage of CKD and excluded patients with heavy proteinuria. Consequently, it is unclear whether THRT is also beneficial in such patients at high risk for the progression of kidney disease. Nevertheless, we showed that the rate of eGFR decline was also significantly abrogated by L-thyroxine supplement in patients with stage 3-4 CKD, suggesting that THRT may indeed be of help in ameliorating the progression of CKD even in these high-risk patients. Finally, since the results of echocardiography and FMD were not included in the analysis, it is difficult to clarify the exact mechanism by which thyroid hormone attenuated the decline in renal function. In spite of these limitations, we believe that the current study is meaningful, as it provides evidence that thyroid hormone benefits renal function preservation in CKD patients with $\mathrm{SCH}$.

In conclusion, THRT abrogated the rate of decline in renal function in CKD patients with $\mathrm{SCH}$, suggesting that Lthyroxine supplement may delay reaching end-stage renal disease in these patients. Therefore, thyroid hormone treatment should be considered for this patient population. 


\section{Acknowledgments}

This work was supported by the Brain Korea 21 Project for Medical Science, Yonsei University, by a National Research Foundation of Korea (NRF) grant funded by the Korean government (MEST; no. 2011-0030711), and by a grant of the Korea Healthcare Technology R\&D Project, Ministry of Health and Welfare, Republic of Korea (A102065).

\section{Author Disclosure Statement}

The authors have nothing to disclose.

\section{References}

1. Mariani LH, Berns JS 2012 The renal manifestations of thyroid disease. J Am Soc Nephrol 23:22-26.

2. Iglesias P, Diez JJ 2009 Thyroid dysfunction and kidney disease. Eur J Endocrinol 160:503-515.

3. Freeston J, Gough A 2004 Reversible myopathy and renal impairment. J R Soc Med 97:124-125.

4. Makino Y, Fujii T, Kuroda S, Inenaga T, Kawano Y, Takishita S 2000 Exacerbation of renal failure due to hypothyroidism in a patient with ischemic nephropathy. Nephron 84:267-269.

5. Mooraki A, Broumand B, Neekdoost F, Amirmokri P, Bastani B 2003 Reversible acute renal failure associated with hypothyroidism: report of four cases with a brief review of literature. Nephrology (Carlton) 8:57-60.

6. Biondi B, Cooper DS 2008 The clinical significance of subclinical thyroid dysfunction. Endocr Rev 29:76-131.

7. Asvold BO, Bjoro T, Vatten LJ 2011 Association of thyroid function with estimated glomerular filtration rate in a population-based study: the HUNT study. Eur J Endocrinol 164:101-105.

8. Chen HS, Wu TE, Jap TS, Lu RA, Wang ML, Chen RL, Lin HD 2007 Subclinical hypothyroidism is a risk factor for nephropathy and cardiovascular diseases in type 2 diabetic patients. Diabet Med 24:1336-1344.

9. Chonchol M, Lippi G, Salvagno G, Zoppini G, Muggeo M, Targher G 2008 Prevalence of subclinical hypothyroidism in patients with chronic kidney disease. Clin J Am Soc Nephrol 3:1296-1300.

10. Lo JC, Chertow GM, Go AS, Hsu CY 2005 Increased prevalence of subclinical and clinical hypothyroidism in persons with chronic kidney disease. Kidney Int 67:1047-1052.

11. den Hollander JG, Wulkan RW, Mantel MJ, Berghout A 2005 Correlation between severity of thyroid dysfunction and renal function. Clin Endocrinol (Oxf) 62:423-427.

12. Caraccio N, Ferrannini E, Monzani F 2002 Lipoprotein profile in subclinical hypothyroidism: response to levothyroxine replacement, a randomized placebo-controlled study. J Clin Endocrinol Metab 87:1533-1538.

13. Monzani F, Di Bello V, Caraccio N, Bertini A, Giorgi D, Giusti C, Ferrannini E 2001 Effect of levothyroxine on cardiac function and structure in subclinical hypothyroidism: a double blind, placebo-controlled study. J Clin Endocrinol Metab 86:1110-1115.

14. Ripoli A, Pingitore A, Favilli B, Bottoni A, Turchi S, Osman NF, De Marchi D, Lombardi M, L'Abbate A, Iervasi G 2005
Does subclinical hypothyroidism affect cardiac pump performance? Evidence from a magnetic resonance imaging study. J Am Coll Cardiol 45:439-445.

15. Surks MI, Ortiz E, Daniels GH, Sawin CT, Col NF, Cobin RH, Franklyn JA, Hershman JM, Burman KD, Denke MA, Gorman C, Cooper RS, Weissman NJ 2004 Subclinical thyroid disease: scientific review and guidelines for diagnosis and management. JAMA 291:228-238.

16. Shin DH, Lee MJ, Kim SJ, Oh HJ, Kim HR, Han JH, Koo HM, Doh FM, Park JT, Han SH, Yoo TH, Kang SW 2012 Preservation of renal function by thyroid hormone replacement therapy in chronic kidney disease patients with subclinical hypothyroidism. J Clin Endocrinol Metab 97: 2732-2740.

17. National Kidney Foundation 2002 K/DOQI clinical practice guidelines for chronic kidney disease: evaluation, classification, and stratification. Am J Kidney Dis 39:S1-S266.

18. Saini V, Yadav A, Arora MK, Arora S, Singh R, Bhattacharjee J 2012 Correlation of creatinine with TSH levels in overt hypothyroidism - a requirement for monitoring of renal function in hypothyroid patients? Clin Biochem 45:212-214.

19. Song SH, Kwak IS, Lee DW, Kang YH, Seong EY, Park JS 2009 The prevalence of low triiodothyronine according to the stage of chronic kidney disease in subjects with a normal thyroid-stimulating hormone. Nephrol Dial Transplant 24:1534-1538.

20. Crowley WF Jr, Ridgway EC, Bough EW, Francis GS, Daniels GH, Kourides IA, Myers GS, Maloof F 1977 Noninvasive evaluation of cardiac function in hypothyroidism. Response to gradual thyroxine replacement. N Engl J Med 296:1-6.

21. Villabona C, Sahun M, Roca M, Mora J, Gomez N, Gomez JM, Puchal R, Soler J 1999 Blood volumes and renal function in overt and subclinical primary hypothyroidism. Am J Med Sci 318:277-280.

22. Cikim AS, Oflaz H, Ozbey N, Cikim K, Umman S, Meric M, Sencer E, Molvalilar S 2004 Evaluation of endothelial function in subclinical hypothyroidism and subclinical hyperthyroidism. Thyroid 14:605-609.

23. Lekakis J, Papamichael C, Alevizaki M, Piperingos G, Marafelia P, Mantzos J, Stamatelopoulos S, Koutras DA 1997 Flow-mediated, endothelium-dependent vasodilation is impaired in subjects with hypothyroidism, borderline hypothyroidism, and high-normal serum thyrotropin (TSH) values. Thyroid 7:411-414.

Address correspondence to: Shin-Wook Kang, MD, PhD

Department of Internal Medicine, College of Medicine, Severance Biomedical Science Institute Brain Korea 21

Yonsei University

134 Shinchon-Dong Seodaemoon-Gu Seoul, 120-752 South Korea

E-mail: kswkidney@yuhs.ac 